\title{
LIQUID PETROLATLM*.
}

\author{
JOSEPII P. REMINGTON.
}

The war in Europe has caused considerable difficulty in obtaining Liquid Petrolatum of the quality suited for internal administration.

The great clemand for this liquid has, of course. stimulated American manufacturers of petrolcum prodicts to prodluce an article equal to the "Russian Mineral Oil" as it is called.

It has been stated that the latter, owing to its having been procured from oils of the naphthene series possesses qualities which fit it for internal use, while the American Oil, being obtained from the methane series, cannot be refined so as to produce an article equal to the Russian Oil. Attempts have been made from time to timc, during the last few years, in this direction but so far with varying success.

An Anerican Oil is coming into use and undoubtedly a way will be found to solve the problem. The points which at present are dwelt upon are these: Specific gravity, viscosity, freeclom from taste, absence of sulphur, and fluorescence.

Specific Grazity-The question of specific gravity need not be vital. It appears that the oil from American source is of a lower specific gravity than that furnished from the Russian sources. Medical writers on the subject insist upon a heavy oil, but if the other requirements are thoroughly carried out, a wider range of admitting oils of lower specific gravity could be dirceted by the Pharmacopoeia.

Yiscosity.-The degree of viscosity seems to be of more importance than specific gravity. For oils to be used for internal usc, a high degrec of viscosity is believed to produce an oil which will not cause lcakage through the rectum. On the other hand, some medical authorities believe that viscosity has nothing whatever to do with leakage. but that this is due to the patient using an excess. The manufacturers are trying hard to satisfy the requirements for viscosity and some are succeeding.

Freedom from tastc is, in the writer's opinion. of the greatest importance, and to produce an oil fully meeting this requircment causes the manufacturer more trouble than anything else. Americans almost universally dislike the taste of coal oil and when the slightest amount of sulphur is present, hydrogen sulphide or similar compounds are produced in the stomach and the disagreeable taste of the eructations renders the product unsalable, and its rotten egg flavor is unbearable.

Fluorescence.-The property which some liquids possess of emitting colors while light is being passed through them, in other words fluorescence, is regarded by dealers as one of the best practical tests to determine a proper degree of refinement. Fluorescent oils are rejected because this quality is believed to indicate lack of purity. Whether a slight fluorescence is a disadvantage medicinally, provided the oil is tasteless, is yet a question to be determined. In the work of revision of the Pharmacopoeia, many samples have been submitted to the writer and the fact stands out prominently that samples of oils of American manufacture have with

* Read at the mecting of the Pcnnsylvania Pharmaceutical Association, June, 1915. 
few exceptions failed to retain the properties of tastelessness and freedom from odor. There is also a tendency to become yellowish or yellowish-brown in time. It would seem from some experiments which have been made that exposure to direct sunlight causes discoloration. This is remarkable because exposure to sunlight has been regarded for centuries as inducing a bleaching or decolorizing effect on most substances. At present it would seem that manufacturers of American oil have not entirely mastered the problems of purification.

At present buyers of American Liquid Petrolatum should be cautious about laying in a stock of the Oil in large lots, for they are likely to find that the last portions have acquired propertics which will render it unsalable, since the slightest coal oil taste makes it unfit for internal administration.

The writer has faith in the American manufacturers' ability to overcome these defects and the greatest encouragement should be given them to produce an American Oil suitable for all purposes.

The new Pharmacopoeia will cover these points by appropriate tests. The sulphuric acid test to determine the presence of carbonizable impurities; the lead oxide test for sulphur compounds; a test for absence of acidity or alkalinity, and the physical tests to determine the tastelessness and frecdom from odor and fluorescence will be given. A light Liquid Petrolatum will also be official for use in atomizers and nebulizers.

The definition will be changed simply to read, "A mixture of liquid hydrocarbons" as it is unneccssary to specify the source from which it is derived, either the methane or naphthene series.

\section{FATS AND OIJ.S.*}

The Adaptability of the Röse-Gottlieb Method for the Estimation of Fat and Oil in Certain Pharmaceutical Preparations.

CHARLES A. HACKMAN, F. I. C.

Judging from statements recorded in past numbers of this journal (Chemist and Druggist), it does not appear to be generally known that the Röse-Gottlieb method affords the most rapid and accurate means for the determination of oil in many pharmaceutical materials and preparations. For example, the estima-

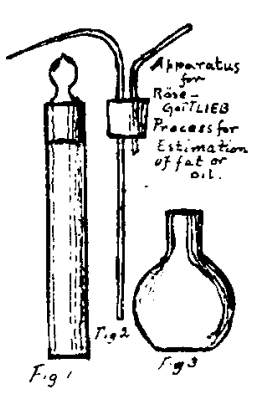
tion of oil in cod-liver oil and malt presents many difficulties when the usual method of extraction with immiscible solvents is attempted; but with the Röse-Gottlieb method, suitably adapted, these difficulties are readily overcome, and the present note has been written with a view to drawing attention to the excellence and wide adaptability of the process. Originally designed by Gottlieb for the estimation of fat in milk (Analyst, 1898, 259), and subsequently modified by Röse, the method was prominently brought before analysts by H. Droop Richmond in "The Analyst" for October, 1908, p. 389. In that communication its suitability for the estimation of fat in dried milks was

* Chemist and Druggist, July 3, 1915. 